\title{
EFFECT OF THE ADDITION OF WASTE SAWDUST ON THERMOPLASTIC PROPERTIES OF A COAL
}

M.G. Montiano C. Barriocanal*, R. Alvarez

Instituto Nacional del Carbón, INCAR-CSIC, Apartado 73, 33080 Oviedo. Spain

*Corresponding author. Tel: +34 9851190 90; Fax:+34 9852976 62; e.mail address: carmenbr@incar.csic.es

\section{ABSTRACT}

Three different sawdusts obtained as wastes from the furniture and flooring industry were selected to study their influence on coal thermoplastic properties. A bituminous coal with a high volatile matter content was chosen as base coal. To investigate the effect of reducing the oxygen content of the sawdusts upon the coal's properties, the sawdusts were heat treated to $250{ }^{\circ} \mathrm{C}$. Blends of the coal with the three as-received and then heat-treated sawdusts were tested. In order to gain a better insight into the subject, the sawdusts were pyrolyzed at $400{ }^{\circ} \mathrm{C}$ to determine the effect of the resulting char and bio-oil upon the plastic properties of the base coal. The Gieseler curves corresponding to the coal-sawdust blends were calculated from the curves corresponding to the coal-char and coal-bio-oil blends. The errors obtained were in all six cases lower than the repeatability allowed by the ASTM standard for the Gieseler test. Considering that the effect of the additives is the sum of both chemical and physical effects, it was possible to evaluate the contribution of each of these to the reduction of coal fluidity. In all cases it was found that the physical effects were more important. The textural properties of the chars obtained at $400{ }^{\circ} \mathrm{C}$ from the biomass were found to be important for determining the influence of biomass on the coal fluidity.

Keywords: Coal, waste biomass, thermoplastic properties, Gieseler test. 


\section{Introduction}

Integrated Steel works are known to release a large amount of greenhouse gases [14]. This industry consumes a large amount of fossil fuels both as a source of heat and energy and as reducing agent. This double function makes it more difficult to control the use of fossil fuels. One way to reduce $\mathrm{CO}_{2}$ emissions is to introduce wastes that, at present are incinerated, as a reducing agent in the blast furnace. In fact, waste plastic is nowadays commercially available as a reducing agent [5] in various industrial plants. The introduction of waste plastic in coal blends for use in cokemaking has also been studied in recent years as a way to recycle plastic and to reduce $\mathrm{CO}_{2}$ emissions [6-8]. The introduction into coal blends of carbon neutral materials like biomass has also been considered as a viable alternative [2,9, 10]. In fact different types of additives are commonly employed in cokemaking [11-15]. These additives include wastes of different origins and with a high carbon content, non-coking coals and bituminous products. Generally speaking the purpose of these additives is to recycle wastes, to reduce costs, to improve coke properties and to exploit other carbon sources that are able to act as reductant in blast furnaces. Considering that the thermoplastic properties of a coal are fundamental for the development of the coke structure and for its final properties, a knowledge of how these properties are modified due to the addition of additives is decisive prior to their use. One of the factors known to affect a coal's thermoplastic properties is the chemical composition of the additive since, the amount of heteroatoms, hydroaromatic and highly condensed aromatic structures present in the reacting media affects the coal's plastic stage. Coal plasticity varies as a function of rank: In low rank coals which soften on heating but do not form anisotropic carbon the high oxygen content increases the reactivity of the carbonizing system giving rise to isotropic structures [16]. Other studies [17] postulate that the formation of oxygen cross linkages which form during carbonization limit the extent of the thermal depolymerization of the coal, inhibiting the formation of lamellar large enough to maintain the fluidity of the system. Biomass has a high oxygen content which has been considered as a drawback for its use in energy production 
processes [18]. However, heating biomass to temperatures between $250-300{ }^{\circ} \mathrm{C}$ produces a decrease in oxygen content making it more suitable for use in energy production.

The aim of the present work is to compare the effect of the addition of heat-treated and as-received biomass on a coal's thermoplastic properties and to establish the contribution of the char and bio-oil derived from the biomass during carbonization to the global effect of the sawdust.

\section{Experimental}

\subsection{Materials}

Three sawdust wastes: SC1 (chestnut), SR1 (oak) and SP1 (pine), from furniture and flooring factories were used as additives. SC1 and SR1 correspond to deciduous wood, while SP1 corresponds to coniferous wood. A coal (G) normally used for metallurgical coke production was selected as the base for the blends. The sawdusts were heated at $5{ }^{\circ} \mathrm{C} / \mathrm{min}$ up to $250{ }^{\circ} \mathrm{C}$ with a soaking time of 30 minutes in a horizontal oven under a $\mathrm{N}_{2}$ flow of 250 $\mathrm{ml} / \mathrm{min}$ to avoid oxidation in order to produce samples SC1 250, SR1 250 and SP1 250. Proximate analyses were performed following the ISO562 and ISO1171 standard procedures for volatile matter and ash content, respectively. The elemental analysis was determined with the aid of a LECO CHN-2000 for C, H and N, a LECO S-144 DR for sulphur and a LECO VTF-900 for the direct determination of oxygen.

\subsection{Thermogravimetric analysis (TG/DTG).}

The TG/DTG analysis of the coal and the sawdusts as-received and heated to $250{ }^{\circ} \mathrm{C}$ were carried out using a TA Instruments SDT 2960 thermoanalyser. Samples of 10-15 mg with a particle size of $<0.212 \mathrm{~mm}$ were heated to $1000^{\circ} \mathrm{C}$ at a rate of $3^{\circ} \mathrm{C} / \mathrm{min}$ under a nitrogen flow of $100 \mathrm{ml} / \mathrm{min}$. From the data obtained by thermogravimetric analysis the volatile matter evolved up to a specific temperature (VMT) and the derivative of the weight loss curve (DTG curve) was calculated. The volatile matter evolved in a specific temperature range was calculated as the difference between the volatile matter evolved up to two specified temperatures (VMT1-T2). In 
addition, Tmax, the temperature of maximum volatile matter evolution was derived from the TG/DTG curves [19].

\subsection{Assessment of coal thermoplastic properties}

The thermoplastic properties of the base coal and of the blends containing $2 \mathrm{wt} \%$ of each of the sawdusts were measured by means of the Gieseler test (ASTM D2639-74). Sawdust and chars with a particle size lower than $0.425 \mathrm{~mm}$ were added. The sample was heated at $3{ }^{\circ} \mathrm{C} / \mathrm{min}$ up to a final temperature of $550{ }^{\circ} \mathrm{C}$, while a constant torque was applied to the stirrer inside the crucible containing the sample. The spin rate of the stirrer was measured continuously until it stopped. The parameters derived from this test were: (i) softening temperature, Ts; (ii) the temperature of maximum fluidity, Tf; (iii) resolidification temperature, Tr; (iv) plastic range, Tr-Ts, which is defined as the difference between the resolidification and softening temperatures; and ( $v$ ) maximum fluidity, MF, expressed as dial divisions per minute (ddpm).

\subsection{Pyrolysis of the sawdusts}

A sample of 6-8 $\mathrm{g}$ was heated in a horizontal electrically-heated oven at $5{ }^{\circ} \mathrm{C} / \mathrm{min}$ to a final temperature of $400{ }^{\circ} \mathrm{C}$. After pyrolysis, the liquid products were collected using an icecooled trap and recovered by solvent extraction with dichloromethane (DCM). The char and liquid product yields were calculated as the weight percentage relative to the starting material and the gas yield was calculated by difference.

\subsection{Textural characterization}

The particle size used for the determination of the porous structure of the chars produced at $400{ }^{\circ} \mathrm{C}$ was lower than $0.212 \mathrm{~mm}$. The true density $\left(\rho_{\mathrm{He}}\right)$ of the chars was measured by means of helium pycnometry in a Micromeritics Accupyc 1330 Pycnometer. Their apparent density $\left(\rho_{\mathrm{Hg}}\right)$ was determined with mercury at $0.1 \mathrm{MPa}$ in a Micromeritics autopore IV 9500 mercury porosimeter. From the true and apparent densities the open porosity corresponding to pore sizes of less than $12 \mu \mathrm{m}$ was calculated by means of the following equation:

$$
\varepsilon(\%)=\left(1-\frac{\rho_{H g}\left(\mathrm{~g} / \mathrm{cm}^{3}\right)}{\rho_{H e}\left(\mathrm{~g} / \mathrm{cm}^{3}\right)}\right) \cdot 100
$$




\section{Results and discussion}

\subsection{Main characteristics of the materials used}

The results of the proximate and elemental analyses of the raw materials i.e. the base coal, the three sawdusts as-received and the heat-treated sawdusts have been included in Table 1. The coal presents a high volatile matter content (i.e. $32 \mathrm{wt} \% \mathrm{db}$ and $8.3 \mathrm{wt} \% \mathrm{db}$ ). On the other hand the sawdusts have a higher volatile matter and lower ash content. The sulphur content of the biomass is very low. These two characteristics i.e. low sulphur and ash contents are beneficial for coking blends. Heat treatment of the biomass produces a decrease in the volatile matter content which has been reported [20-22] to be due to the decomposition of some reactive components of the hemicellulose. The carbon content increases due to the heat treatment while $\mathrm{N}, \mathrm{H}$ and $\mathrm{S}$ undergo only slight variations. In agreement with the results of other authors [22,23], the most significant variation corresponds to the oxygen content due to the evolution of $\mathrm{CO}$ and $\mathrm{CO}_{2}$. The highest reduction corresponds to SC1 and represents a $36 \%$ decrease. According to the results of the elemental analysis, the $\mathrm{C} / \mathrm{H}$ and $\mathrm{C} / \mathrm{O}$ atomic ratios increase due to the heat treatment. These effects are considered as positive for their use in coking blends.

\subsection{Devolatilization behaviour of the raw materials}

Figure 1 shows the devolatilization profiles corresponding to the as-received $(A R)$, the heat-treated sawdusts (HT) and the coal. The thermal decomposition of SC1, SR1 and SP1 clearly show three different steps: the first one corresponding to the decomposition of hemicellulose in the temperature range between 200 and $300{ }^{\circ} \mathrm{C}$; the second one corresponding to the decomposition of cellulose in the temperature range between 275 and $350{ }^{\circ} \mathrm{C}$; and the last one corresponding to the decomposition of lignin. The lignin decomposes over a broad temperature range between 280 and $500{ }^{\circ} \mathrm{C}$ with the maximum rate at around $400{ }^{\circ} \mathrm{C}[24,25]$. Whereas hemicellulose and cellulose present a high devolatilization rate over a narrow temperature range, the thermal decomposition of lignin takes place over a wider temperature range that commences at a lower temperature than 
cellulose. The coal loses most of its volatile matter in the range between 400 and $500{ }^{\circ} \mathrm{C}$. Heating the biomass to $250{ }^{\circ} \mathrm{C}$ gives rise to the decomposition of its hemicellulose which is apparent in Figure 1 because the first devolatilization step disappears in the curve corresponding to SC1 250, SR1 250 and SP1 250. This process involves the evolution of $\mathrm{H}_{2} \mathrm{O}$ and carbon oxides ( $\mathrm{CO}$ and $\mathrm{CO}_{2}$ ) and is reflected in the elemental composition of the heat-treated biomass (Table 1). Studies carried out [26] on the pyrolysis of the three main components of wood (i.e. hemicellulose, cellulose and lignin) are in agreement with the results of this work which shows that hemicellulose is the first to decompose, this occurring at a low temperature whereas the decomposition of cellulose occurs between 315 and 400 ${ }^{\circ} \mathrm{C}$. Lignin decomposition occurs between ambient temperature and $900{ }^{\circ} \mathrm{C}$. The parameters derived from the thermogravimetric analysis have been included in Table 2. The decomposition of hemicelullose takes place at 267 and $266{ }^{\circ} \mathrm{C}$ for SC1 and SR1, while in the case of SP1 it occurs at a slightly higher temperature $302{ }^{\circ} \mathrm{C}$. The same occurs in the decomposition of cellulose and lignin which takes place at a slightly higher temperature for SP1 than for the deciduous woods. As expected, the volatile matter evolved up to $300{ }^{\circ} \mathrm{C}$ decreases with sawdust heat-treatment and is accompanied by an increase in the volatile matter evolved in the range where the coal evolves most of its volatile matter i.e. between $400-500{ }^{\circ} \mathrm{C}$, which increases the possibilities of interaction. The char yield also increases especially in the case of SR1 and SP1.

\subsection{Influence of biomass on coal thermoplastic properties}

One of the most important properties of coal in relation to coking is the plastic stage. Consequently the influence of any additive on a coal's thermoplastic properties must be tested before it is used in coking blends. In a previous study [27] the variation of coal thermoplastic properties due to the addition of 2 and $5 \mathrm{wt} . \%$ of sawdust was studied with coals of 18 and $23 \mathrm{wt} \%$.db volatile matter content. The results showed that a $2 \mathrm{wt} . \%$ addition produced a decrease in fluidity of between 40 and $50 \%$ depending on the sawdust and the type of coal and that $5 \mathrm{wt} . \%$ produced a decrease of between 70 and $85 \%$. For this reason a 
high fluidity coal was chosen for the present study and only a 2 wt.\% level addition was applied.

Figure 2 shows the variation of the Gieseler fluidity with temperature for coal $G$ and the blends of coal $\mathrm{G}$ with $2 \mathrm{wt} . \%$ of SC1, SR1 and SP1. It is clear from the Figure that the addition of only $2 \mathrm{wt} . \%$ of any of the three sawdusts selected produced a drastic reduction in coal fluidity. If coal $\mathrm{G}$ presented a maximum Gieseler fluidity of around $4000 \mathrm{ddpm}$, any of the biomasses tested halved it. Although all three types of sawdust had a great effect on coal plasticity the following order for deleterious effect was established: SC1>SR1>SP1. The softening temperature increased with the additives, although no clear trend was observed for the plastic range. The effect of heat-treating the biomass was also tested at the level $2 \mathrm{wt} . \%$ addition (Figure 2). Heating the sawdusts to $250{ }^{\circ} \mathrm{C}$ effectively reduced their oxygen content. The addition of the heat treated sawdust to the coal produced in both cases a greater reduction than that of the non-treated sawdust. In other words the effect of the sawdusts which have been heat treated was more deleterious than the original sawdust. The deleterious effect of heteroatoms like oxygen for the development of a coal's thermoplastic properties is well-known $[16,28]$. The softening of coal has been related $[28,29]$ to a physical melting process without involvement of the covalent network. Increasing the temperature initiates the rupture of carbon/carbon bonds which leads to the formation of the plastic phase. This system needs to be stabilized with the help of hydrogen transfer reactions. Condensation of the free radicals formed will lead to the formation of a semicoke. These condensation reactions may be retarded by the presence of large quantities of polycondensed aromatic structures that help to stabilize the free radicals formed. On the other hand the presence of heteroatoms in the system will lead to higher reactivity, quicker condensation and lower fluidity. The presence of oxygen affects aromatization processes because oxygen is an initiator of the formation of activated centres for cyclization and the consecutive cyclization of these centres is inhibited by oxygen because of enchanced activation energy [30]. In the present case the reduction of the amount of oxygen in the additive was not decisive. It must be borne in mind that HT sawdusts still contain a high 
percentage of oxygen in the range between 28 and $35 \mathrm{wt} . \% \mathrm{db}$. Nevertheless it should be remembered that heat-treated samples evolve a greater percentage of its volatile matter during the coal plastic stage (Table 2) so that there is more possibility they will interact with the volatiles evolved from the coal. It was established that the diminution of oxygen content due to heat-treatment of the sawdust does not lead to a less deleterious effect on coal plasticity.

The effect of carbonaceous additives on coal plastic properties can be considered a combination of two factors: on the one hand, the chemical interaction between the coal devolatilization products and the volatiles evolved by the additives during heating and on the other, the physical adsorption by the additive of the products responsible for the thermoplasticity of a coal. The inert additive that is blended with the softening coal may have the effect of reducing fluidity by adsorbing the primary decomposition products that act as coal plasticiziers $[29,31,32]$

To clarify the chemical and physical implications of the results obtained, the sawdust was pyrolyzed to $400{ }^{\circ} \mathrm{C}$ and the char and bio-oil produced were recovered to see the effect of adding of these two products, separately, upon the coal's plastic properties. A temperature of $400{ }^{\circ} \mathrm{C}$ was chosen because this is the temperature at which the coal starts to soften.

Figure 3 shows the mass balance corresponding to the pyrolysis of the three sawdusts as-received and heat-treated to $250{ }^{\circ} \mathrm{C}$. In the case of the as-received sawdust the highest yield corresponds to bio-oil. The behaviour of the three sawdusts is similar although SP1 produces a lower amount of char. In contrast the heat-treated biomass produced char as a major product of pyrolysis, the yield of bio-oil being lower than in the case of the asreceived sawdust. The yield of gas was slightly lower for heat-treated samples. The amount of char that is present with the coal when it reaches its softening temperature i.e. $400{ }^{\circ} \mathrm{C}$ is higher in the case of heat-treated sawdust for the same level of addition to the coal. It is also higher for SC1 and SR1 than for SP1.

Blends of coal G containing 2 wt. $\%$ of the char and the bio-oil obtained at $400{ }^{\circ} \mathrm{C}$ from the as-received and the heat-treated sawdust were prepared and their fluidity compared to 
that of G. All the additives produced a decrease in maximum coal fluidity. The loss is shown in Figure 4a for the as-received samples and in Figure 4b for the heat-treated ones. It is clear from the graphs that in both cases (i.e. the as-received (AR) and heat-treated (HT) samples), the effect of the sawdust is greater than that of the char or the bio-oil. In fact, the maximum fluidity loss due to the effect of the bio-oil is very low, around $10 \%$ for the AR sawdust and between 10 and $20 \%$ for the bio-oil derived from the HT sawdusts. The heat treatment of sawdust to $250{ }^{\circ} \mathrm{C}$ mainly produces the decomposition of hemicellulose which involves the loss of compounds such as water, methanol, formic and acetic acids [33]. Non-condensable products are also evolved. These include carbon dioxide, carbon monoxide and smaller amounts of methane [34]. The bio-oil from the heat-treated samples contains a lower amount of water and volatile compounds. Consequently the possibility of interaction with the coal will be higher making its effect more deleterious. The effect of the addition of the char obtained at $400{ }^{\circ} \mathrm{C}$ from both types of sawdusts (i.e. AR and HT) is very similar with percentages of diminution of maximum fluidity in the range of 30 to $40 \%$. The results clearly show that to explain the effect of the addition of biomass to a coal's plastic properties, the influence of the char must be considered more important than that of the bio-oil.

With the aid of Gieseler fluidity curves of the blends of coal with char and bio-oil obtained from biomass pyrolysis and of the blend with the whole sawdust, an attempt was made to construct the theoretical Gieseler fluidity curve of the blend of coal with sawdust from the experimental curves of the blends of coal with the sawdust pyrolysis products in order to determine the contribution of each component (i.e. char and bio-oil), to the total reduction of the coal fluidity. First of all the experimental fluidity data were transformed into mathematical equations. Considering that the shape of the Gieseler curves fit into a Gaussian type curve, the experimental data of all the Gieseler experiments corresponding to the base coal and its blends with the three sawdusts AR and HT and with the bio-oil and the char derived from the pyrolysis were transformed into equations with the form:

$$
\mathrm{Y}=\mathrm{y}_{0}+\mathrm{A} \cdot \mathrm{e}^{\wedge}\left(-0.5 \cdot\left(((\mathrm{T}-\mathrm{xc}) / \mathrm{w})^{\wedge} 2\right)\right)
$$


where $Y$ represents the Gieseler fluidity $(\mathrm{ddpm})$ and $\mathrm{T}$ the temperature $\left({ }^{\circ} \mathrm{C}\right)$, the parameters $y_{0}, x c, A$ and $w$ being optimized to resemble the experimental curves. The maximum fluidity derived from equation [1] for each sample fit very well with the experimental ones as shown in Figure 5's correlation coefficient $r^{2}=0.997$. To construct the Gieseler curves corresponding to the blends $\mathrm{G}+2 \%$ of each sawdust $\mathrm{AR}$ and $\mathrm{HT}$, from the corresponding curves of the char and bio-oil obtained from the pyrolysis, it was thought that the Gieseler curve corresponding to the blend of the coal with $2 \mathrm{wt} . \%$ of each sawdust i.e. $G+2 S_{i}$ could be considered as the curve of coal $\mathrm{G}$ minus an optimized factor $\mathrm{K}_{\text {char }}$ multiplied by the Gieseler curve corresponding to $\mathrm{G}+2 \mathrm{Char}_{\mathrm{i}}$ plus another optimized factor $\mathrm{K}_{\text {bio-oil }}$ multiplied by the Gieseler curve corresponding to G+2bio-oil as in Equation [2].

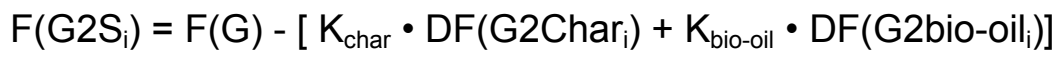

where $F(G 2 S i)$ is the Gieseler curve of each blend $G$ with 2 wt. \% of sawdust, DF(G2Char $i)$ and $\mathrm{DF}\left(\mathrm{G}_{2}\right.$ bio-oil $\left.\mathrm{i}_{\mathrm{i}}\right)$ are the diminution of Gieseler fluidity of coal $\mathrm{G}$ due to the addition of the char and bio-oil obtained from pyrolysis at $400{ }^{\circ} \mathrm{C}$ from each sawdust AR and HT respectively. Table 3 shows the optimized parameters that allow the contribution of the chars and the bio-oils to be evaluated. Averaging the values corresponding to the optimized parameters as a function of the type of additive, the following values are obtained: $\mathrm{K}_{\text {bio-oil }}=$ 0.78 and $K_{\text {char }}=1.30$ for the $A R$ samples and $K_{\text {bio-oil }}=0.21$ and $K_{\text {char }}=1.52$ for the $H T$ samples. It is clear from the parameters that the contribution of the char is higher than that of the biooil and in the case of the HT samples the contribution to the decrease in maximum fluidity is even higher. Table 3 also includes the experimental and calculated values of the maximum fluidity (MF) of the blends. Differences lower than $4 \%$ between the experimental and calculated MF are obtained for the AR samples, while in the case of the HT sawdusts greater errors were obtained specially in the case of SP1-250 and SR1-250 (7 and $9 \%$ respectively). Figure 6 shows the comparison between the experimental and calculated Gieseler curves. 
In a previous research work [32] the importance of the textural characteristics of various additives that had been thermally treated to $900{ }^{\circ} \mathrm{C}$ to avoid interaction between the volatile matter evolved by the additive during co-carbonization was studied and compared with the effect of the whole additive. In the present study it appears that it is the physical effect of the additive (i.e. the presence of a material which has already lost most of its volatiles) which is the important factor. This heat treated material may reduce coal fluidity by absorbing the small-molecular-mass compounds produced when the coal is heated to over $400^{\circ} \mathrm{C}$ and which are responsible for the softening and melting of the coal. To corroborate this finding, the chars 400 were studied in greater depth. Their textural characteristics were determined by means of $\mathrm{He}$ and $\mathrm{Hg}$ pycnometry (Table 4). The values obtained for the true density do not show important differences due to thermal treatment. As for the different types of biomass it appears that the true density of pine sawdust is greater than that of the other two. The values of the apparent density are much lower than those of the true density, indicating a highly porous structure. Thus the porosity values vary between 61 and $66 \%$. Although the differences are small they are significant enough to suggest that heat treatment induces an increase in porosity. The results of this study corroborate those of a previous paper [32] that chars with a higher porosity induce greater reductions in coal fluidity.

\section{Conclusions}

The elemental composition of the additives used in blends with coal for cokemaking, especially the amount of heteroatoms, is known to be important in determining their effect on coal thermoplastic properties due to their influence on the reactivity of the reaction media. In the present study three different sawdusts were found to produce a drastic reduction in fluidity even at 2 wt.\% addition. The sawdusts were subjected to thermal treatment to reduce their oxygen content and this led to a even greater decrease in coal fluidity. Considering that the effect of the additives is the sum of chemical and physical effects, it was possible to evaluate the contribution of each of these effects to the reduction of coal fluidity. In all cases it was found that the physical effects were more important. In addition it was confirmed that 
porosity as determined by $\mathrm{He}$ and $\mathrm{Hg}$ pycnometry is an important parameter for determining the influence of additives on coal fluidity.

\section{Acknowledgements}

The authors are grateful to the Research Fund for Coal and Steel (RFCS) for financial support (Project RFCR-CT-2010-00007). M.G.M. thanks the Government of the Principado de Asturias for the award of a predoctoral grant with funds from the PCTI-Asturias within the Severo Ochoa program. 


\section{References}

[1] IPCC Special Report on Carbon Dioxide Capture and Storage. Prepared by Working Group III of the International Panel on climate change, D Metz, O Davidson, $\mathrm{H}$ de Coninck, M Loos, L Meyer (Eds) Cambridge University Press, 2005.

[2] $\mathrm{Ng} \mathrm{KW}$, MacPhee JA, Giroux L, Todoschuk T. Reactivity of bio-coke with $\mathrm{CO}_{2}$. Fuel Processing Technology 2011;92:801-804.

[3] Ariyama T, Murai R, Ishii J, Sato M. Reduction of CO2 emissions from integrated steel works and its subjects for a future study. ISIJ International 2005;45:1371-1378.

[4] Ariyama T, Sato M. Optimization of ironmaking process for reducing $\mathrm{CO} 2$ emissions in the integrated steel works. ISIJ International 2006;46:1736-1744.

[5] Asanuma M, Ariyama T, Sato M, Murai R, Nonaka T, Okochi I, Tsukiji H, Nemoto K. Development of Waste Plastics Injection Process in Blast Furnace. ISIJ International 2000;40:244-251.

[6] Nomura S, Kato K. The effect of plastic size on coke quality and coking pressure in the co-carbonization of coal/plastic in coke oven. Fuel 2006; 85: 47-56.

[7] Melendi S, Diez MA, Alvarez R, Barriocanal C. Relevance of the composition of municipal plastic wastes for metallurgical coke production. Fuel 2011; 90 1431-1438.

[8] Melendi S, Diez MA, Alvarez R, Barriocanal C. Feedstock recycling of plastic wastes in cokemaking. Fuel 2009; 88: pp. 1937-1944.

[9] MacPhee JA, Gransden JF, Giroux L, Price JT. Possible CO2 mitigation via addition of charcoal to coking coal blends. Fuel Processing Technology 2009;90:16-20.

[10] Emmerich FG, Luengo CA. Reduction of emissions from blast furnaces by using blends of coke and babassu charcoal. Fuel 1994; 73: 1235-1236.

[11] Patrick JW, Stacey AE. The strength of industrial cokes. 7. Further studies of the influence of additives in a coke-oven charge on the tensile strength of coke. Fuel 1978; 57: 258-264. 
[12] Mochida I, Matsuoka H, Korai Y, Fujitsu H, Takeshita K. Carbonization of coals to produce anisotropic cokes. 1. Modifying activities of some additives in the cocarbonization of low-rank coals. Fuel 1982;61: 587-594.

[13] Alvarez R, Pis JJ, Díez MA, Barriocanal C, Canga CS, Menéndez JA. A semi-industrial scale study of petroleum coke as an additive in cokemaking. Fuel Processing Technology 1998; 55: 129-141.

[14] Barranco, R., Patrick, J., Snape, C., Thompson, A. Impact of low-cost filler material on coke quality. Fuel 2007; 86: 2179-2185.

[15] Fernández AM, Barriocanal C, Alvarez R. The effect of additives on coking pressure and coke quality. Fuel 2012; 95:642-647.

[16] Marsh $\mathrm{H}$. The cokemaking process. $51^{\text {st }}$ Ironmaking Conference Proceedings Vol. 51 Toronto 1992 pp. 569-580.

[17] Patrick JW, Green PD, Thomas KM, Walker A. The influence of pressure on the development of optical anisotropy during carbonization of coal. Fuel 1989;68:149-154.

[18] Van der Stelt MJC, Gerhauser H, Kiel JHA, Ptansinski KJ. Biomass upgrading by torrefaction for the production of biofuels: A review. Biomass \& Bioenergy 2011;35:3748-3762.

[19] Barriocanal C, Díez M A, Alvarez R, Casal M D, Canga C S. On the relationship between coal plasticity and thermogravimetric analysis. J. Anal. Appl. Pyrol 2003; 67 (1): 23-40.

[20] Arias B, Pevida C, Fermoso J, Plaza MG, Rubiera F, Pis JJ. Influence of Torrefaction on the grindability and reactivity of woody biomass. Fuel Proc. Technol. 2008;89:169175.

[21] Williams PT, Besler S. The influence of temperature and heating rate on the slow pyrolysis of biomass. Renewable Energy 1996;7:233-250.

[22] Prins MJ, Ptasinski KJ, Janssen FJJg. Torrefaction of wood. Part 1. Weight loss kinetics. Journal of Analytical and Applied Pyrolysis 2006;77:28-34. 
[23] Strezov V, Patterson M, Zymla V, Fisher K, Evans TJ, Nelson PF. Fundamental aspects of biomass carbonisation. Journal of Analytical and Applied Pyrolysis 2007;79:91-100.

[24] Basu P. Biomass gasification and pyrolysis. Practical design and theory. Academic Press 2010.

[25] Melkior T, Jacob S, Gerbaud G, Hediger S, Le Pape L, Bonnefois L, Bardet M. NMR analysis of the transformation of wood constituents by Torrefaction. Fuel 2012; 92: $271-280$.

[26] Yang H, Yan R, Chen H, Lee DH, Zheng Ch. Characteristics of hemicellulose, cellulose and lignin pyrolysis. Fuel 2007;86:1781-1788.

[27] Technical report RFCS project ref: RFCR-CT-2010-00007 March 2011.

[28] Grint A, Mehani S, Trewhella M, Crook MJ. Role and composition of the mobile phase in coal. Fuel 1985;64:1355-1361.

[29] Haberbehl D, Orywal F, Beyer HD. Plastic properties of coal in Elliot M A (Ed.). Chemistry of Coal Utilization, $2^{\text {nd }}$ Supplementary Volume. Wiley Interscience, New York, 1981.

[30] Marsh H, Menendez R. Mechanisms of formation of isotropic and anisotric carbons. In Marsh H (Ed.). Introduction to Carbon Science, Butterworths, 1989.

[31] Sakurovs R. Some factors controlling the thermoplastic behaviour of coals. Fuel 2000; 79:379-389.

[32] Fernández AM, Barriocanal C, Díez MA, Alvarez R. Importance of the textural characteristics of inert additives in the reduction of coal thermoplastic properties. Fuel 2010; 89: 3388-3392.

[33] Prins MJ, Ptasinski KJ, Janssen FJJG. Torrefaction of wood Part 2. Analysis of products. J. Anal. Appl. Pyrolysis 2007;77:35-40.

[34] White RH, Dietenberger MA in: Buschow KHJ, Cahn RW, Flemings MC, Ilschener B, Kramer EJ, Mahajan S. The Encyclopedia of Materials: Science and Technology, Elsevier, Amsterdam, 2001, pp. 9712-9716. 
Table 1. Proximate and ultimate analysis of the raw materials.

\begin{tabular}{lccccccc}
\hline & G & SC1 & SC1-250 & SR1 & SR1-250 & SP1 & SP1-250 \\
\hline VM (wt.\% db) & 32.0 & 78.8 & 58.1 & 81.9 & 65.1 & 84.8 & 74.4 \\
Ash (wt.\%db) & 8.3 & 1.3 & 5.9 & 0.5 & 0.9 & 0.3 & 0.6 \\
$\mathrm{C}(\mathrm{wt} . \% \mathrm{db})$ & 78.3 & 50.2 & 58.8 & 50.2 & 59.8 & 50.7 & 57.6 \\
$\mathrm{H}(\mathrm{wt} . \% \mathrm{db})$ & 4.9 & 5.7 & 4.7 & 5.9 & 4.9 & 6.1 & 5.9 \\
$\mathrm{~N}(\mathrm{wt} . \% \mathrm{db})$ & 2.5 & 0.5 & 0.8 & 0.4 & 0.5 & 0.3 & 0.5 \\
$\mathrm{~S}(\mathrm{wt} \% \% \mathrm{db})$ & 0.88 & 0.00 & 0.03 & 0.02 & 0.04 & 0.00 & 0.02 \\
$\mathrm{O}(\mathrm{wt} . \% \mathrm{db})$ & 4.5 & 43.0 & 27.5 & 44.0 & 33.8 & 42.5 & 35.3 \\
$\mathrm{C} / \mathrm{H}^{2}$ & 1.34 & 0.73 & 1.05 & 0.71 & 1.02 & 0.69 & 0.81 \\
$\mathrm{C} / \mathrm{O}^{2}$ & 23.35 & 1.56 & 2.86 & 1.52 & 2.36 & 1.59 & 2.18 \\
\hline
\end{tabular}

${ }^{1} \mathrm{VM}$, volatile matter content on a dry basis (db). ${ }^{2}$ Atomic ratio. 
Table 2. Parameters derived from the thermogravimetric analysis of the sawdust performed at $3{ }^{\circ} \mathrm{C} / \mathrm{min}$.

\begin{tabular}{|c|c|c|c|c|c|c|c|}
\hline & G & SC1 & SC1-250 & SR1 & SR1-250 & SP1 & SP1-250 \\
\hline$M V 300^{a}$ & 2.2 & 38.5 & 11.0 & 36.4 & 10.5 & 24.8 & 10.7 \\
\hline$M V 400^{a}$ & 12.4 & 79.6 & 52.3 & 82.7 & 67.1 & 85 & 78.4 \\
\hline MV400-500 & 52.5 & 7.4 & 16.7 & 6.3 & 14.2 & 5.4 & 9.2 \\
\hline MV500-750 & 8.4 & 8.4 & 19.5 & 5.9 & 12.8 & 4.2 & 7.3 \\
\hline DTGmax $1^{\mathrm{b}}(\% / \min )$ & - & 1.21 & - & 1.37 & - & 1.70 & - \\
\hline $\mathrm{T} 1 \max ^{\mathrm{C}}\left({ }^{\circ} \mathrm{C}\right)$ & - & 267 & - & 266 & - & 302 & - \\
\hline DTGmax $2^{\mathrm{b}}(\% / \mathrm{min})$ & - & 2.72 & 1.81 & 3.83 & 3.11 & 3.78 & 4.05 \\
\hline $\mathrm{T} 2 \max ^{\mathrm{c}}\left({ }^{\circ} \mathrm{C}\right)$ & - & 314 & 312 & 319 & 316 & 342 & 336 \\
\hline DTGmax $3^{\mathrm{b}}(\% / \mathrm{min})$ & 0.82 & 0.32 & 0.48 & 0.30 & 0.50 & 0.24 & 0.35 \\
\hline $\mathrm{T} 3 \max ^{\mathrm{C}}\left({ }^{\circ} \mathrm{C}\right)$ & 442 & 385 & 389 & 388 & 379 & 405 & 402 \\
\hline$C Y^{d}(\%)$ & 66.4 & 22.9 & 36.5 & 16.5 & 34.5 & 12.9 & 25.7 \\
\hline
\end{tabular}

${ }^{a}$ VMT: volatile matter evolved up to a specific temperature $(T)$ or in a specific temperature range and normalized to $100 \%$.

${ }^{b}$ DTGmax: Rate of maximum volatile matter evolution.

${ }^{\mathrm{c}}$ Tmax: Temperature of maximum volatile matter evolution.

${ }^{\mathrm{d}} \mathrm{CY}$ : Coke yield at $1000^{\circ} \mathrm{C}$. 
Table 3. Optimized parameters used to simulate the Gieseler curves corresponding to the blends of coal G with $2 \mathrm{wt} \%$ of the AR and HT sawdusts and the experimental and calculated values of the maximum Gieseler fluidity for the blends of coal $G$ with $2 \%$ of each sawdust AR and $\mathrm{HT}$.

\begin{tabular}{lcccc}
\hline & $\mathrm{K}_{\text {char }}$ & $\mathrm{K}_{\text {bio-oil }}$ & MF $_{\text {exp. }}$ G2S $(\mathrm{ddpm})$ & MF $_{\text {calc. }}$ G $_{\mathrm{i}}(\mathrm{ddpm})$ \\
\hline SC1 & 1.41 & 1.15 & 1840 & 1835 \\
SR1 & 1.20 & 0.86 & 1994 & 1970 \\
SP1 & 1.30 & 0.34 & 2081 & 1999 \\
SC1-250 & 1.49 & 0.40 & 1569 & 1633 \\
SR1-250 & 1.89 & 0.12 & 1783 & 1910 \\
SP1-250 & 1.17 & 0.12 & 1818 & 1658 \\
\hline
\end{tabular}


Table 4. Parameters derived from $\mathrm{He}$ and $\mathrm{Hg}$ pycnometry of the chars obtained at $400{ }^{\circ} \mathrm{C}$ from the AR and HT sawdusts.

\begin{tabular}{lcccccc}
\hline & SC1 & SC1-250 & SR1 & SR1-250 & SP1 & SP1-250 \\
& 400 & 400 & 400 & 400 & 400 & 400 \\
\hline$\rho_{\mathrm{He}}\left(\mathrm{g} / \mathrm{cm}^{3}\right)$ & 1,364 & 1.371 & 1.391 & 1.399 & 1.438 & 1.435 \\
$\rho_{\mathrm{Hg}}\left(\mathrm{g} / \mathrm{cm}^{3}\right)$ & 0.498 & 0.471 & 0.486 & 0.477 & 0.558 & 0.524 \\
$\varepsilon(\mathrm{vol} \%)$ & 63.5 & 65.7 & 65.1 & 65.9 & 61.2 & 63.5 \\
\hline
\end{tabular}



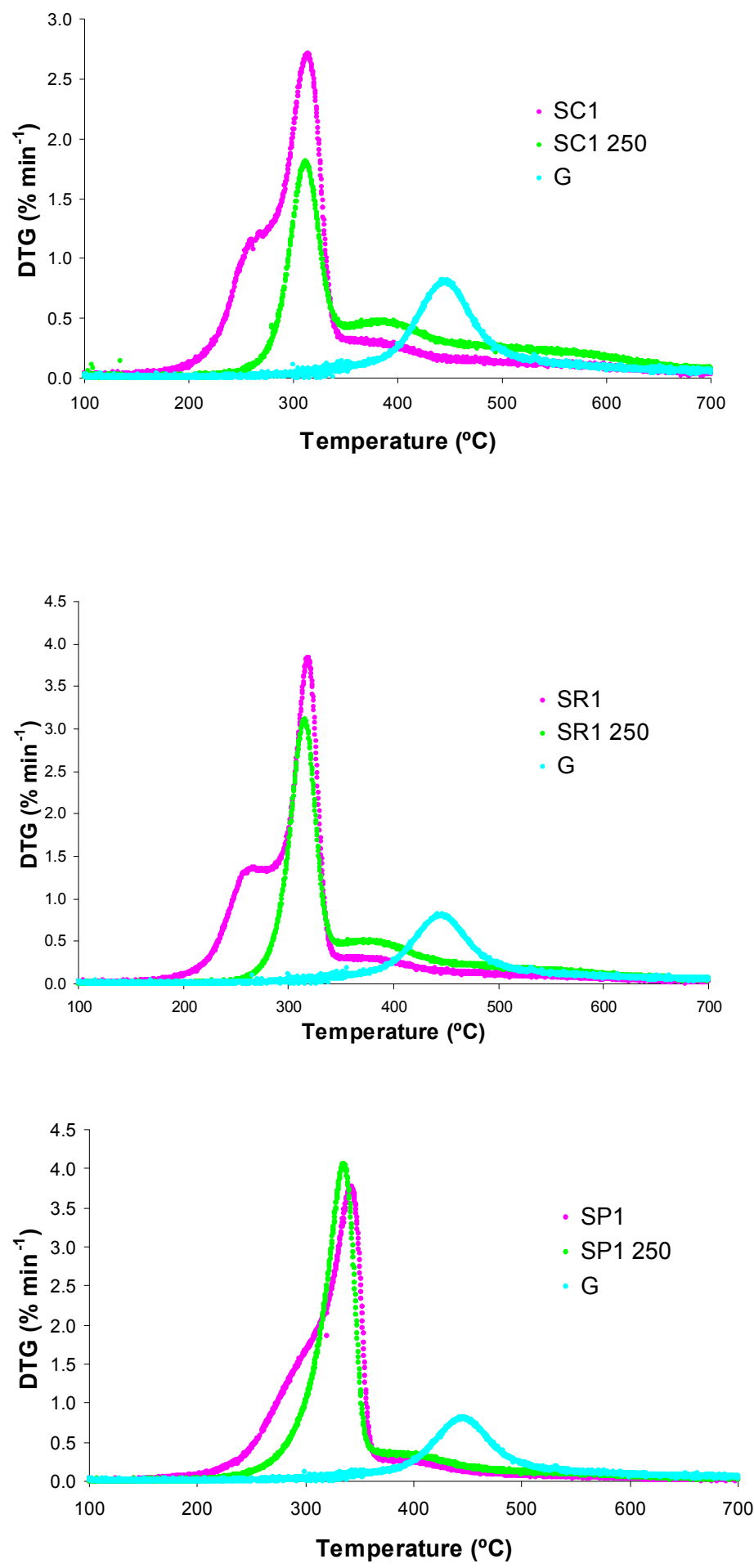

Figure 1. Comparison of the DTG profiles corresponding to the coal and the three asreceived and heat-treated sawdusts. 


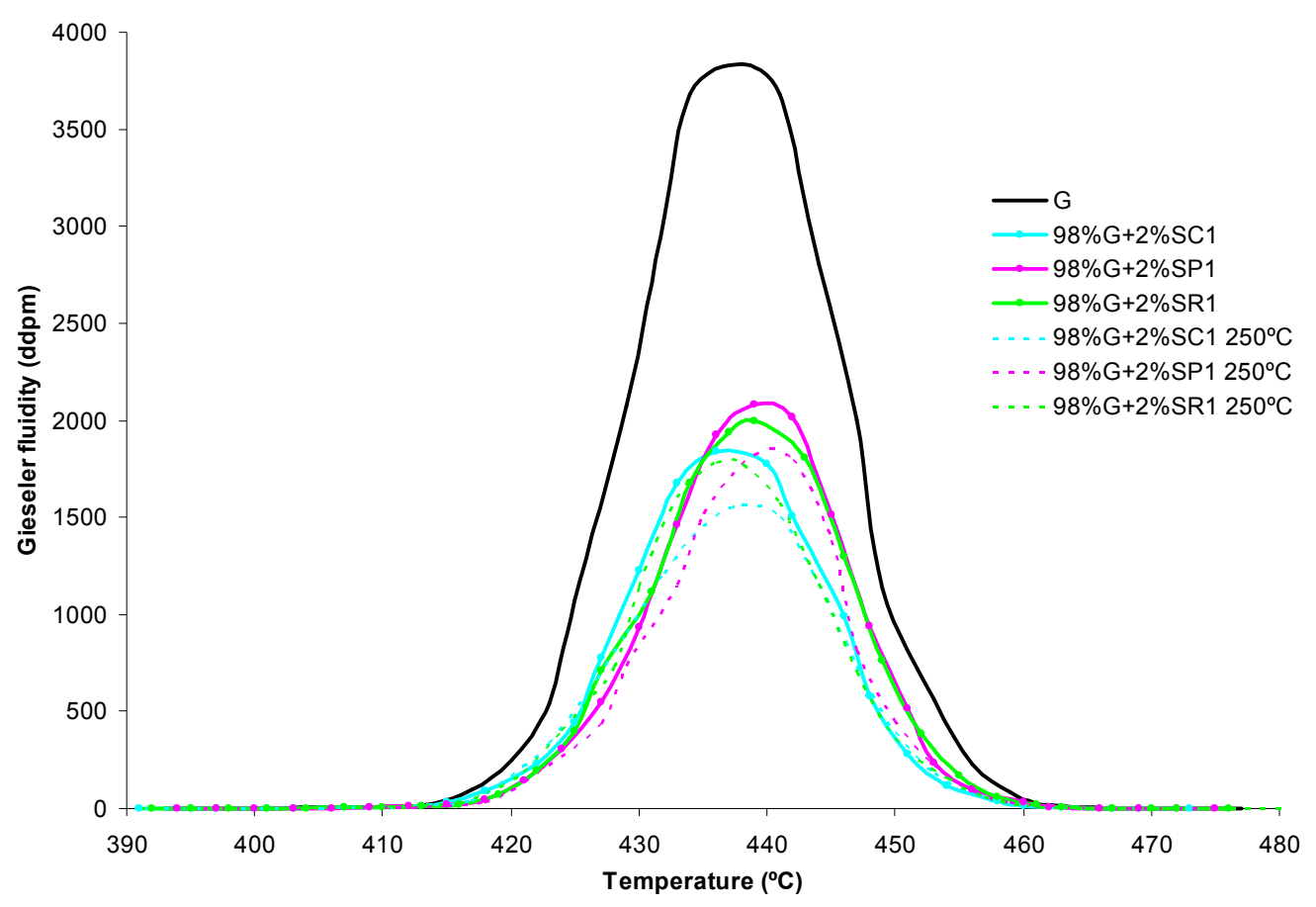

Figure 2. Variation of the Gieseler fluidity of the coal with the addition of the sawdusts. 

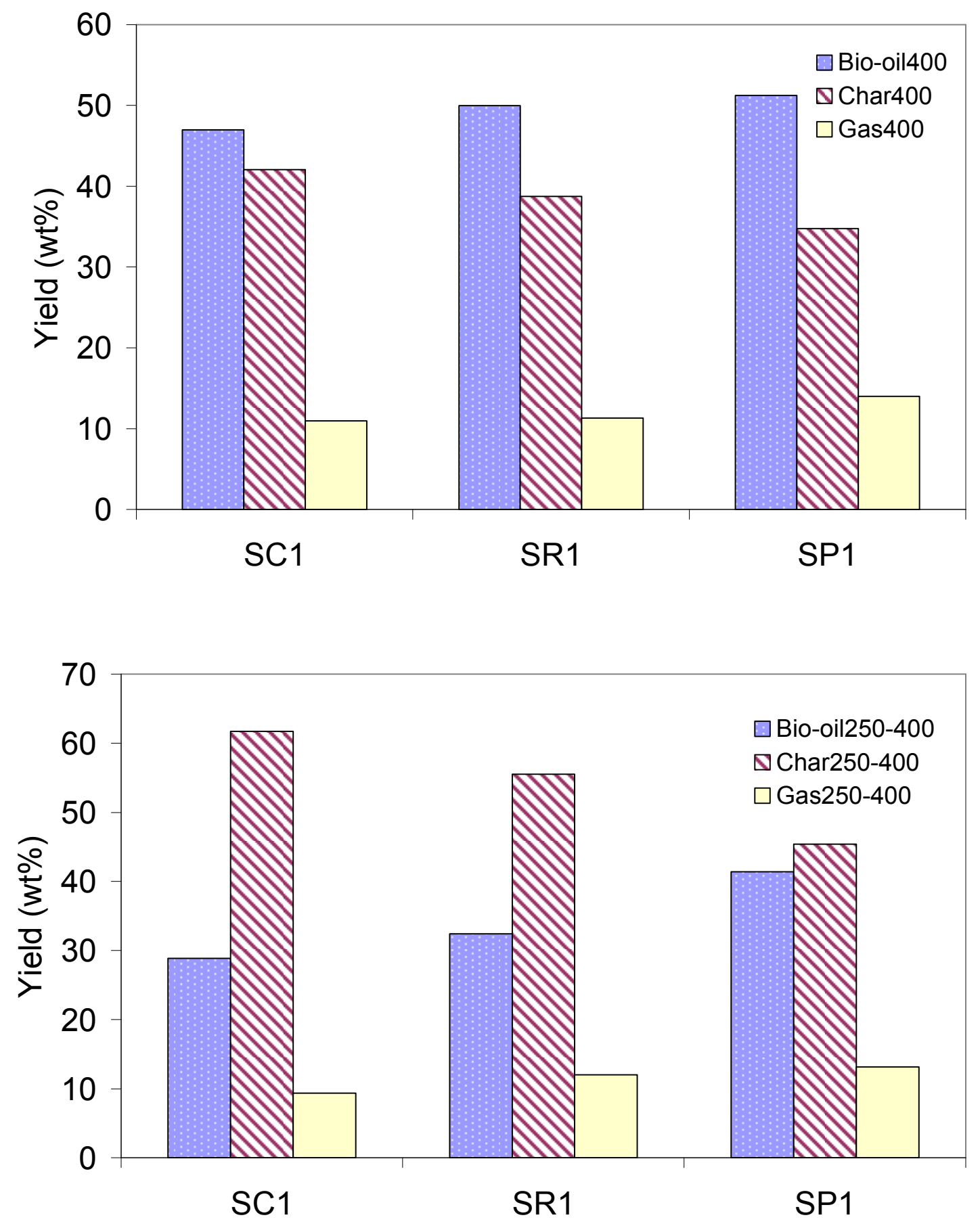

Figure 3. Mass balance corresponding to the pyrolysis at $400^{\circ} \mathrm{C}$ of the as-received and heattreated sawdust. 

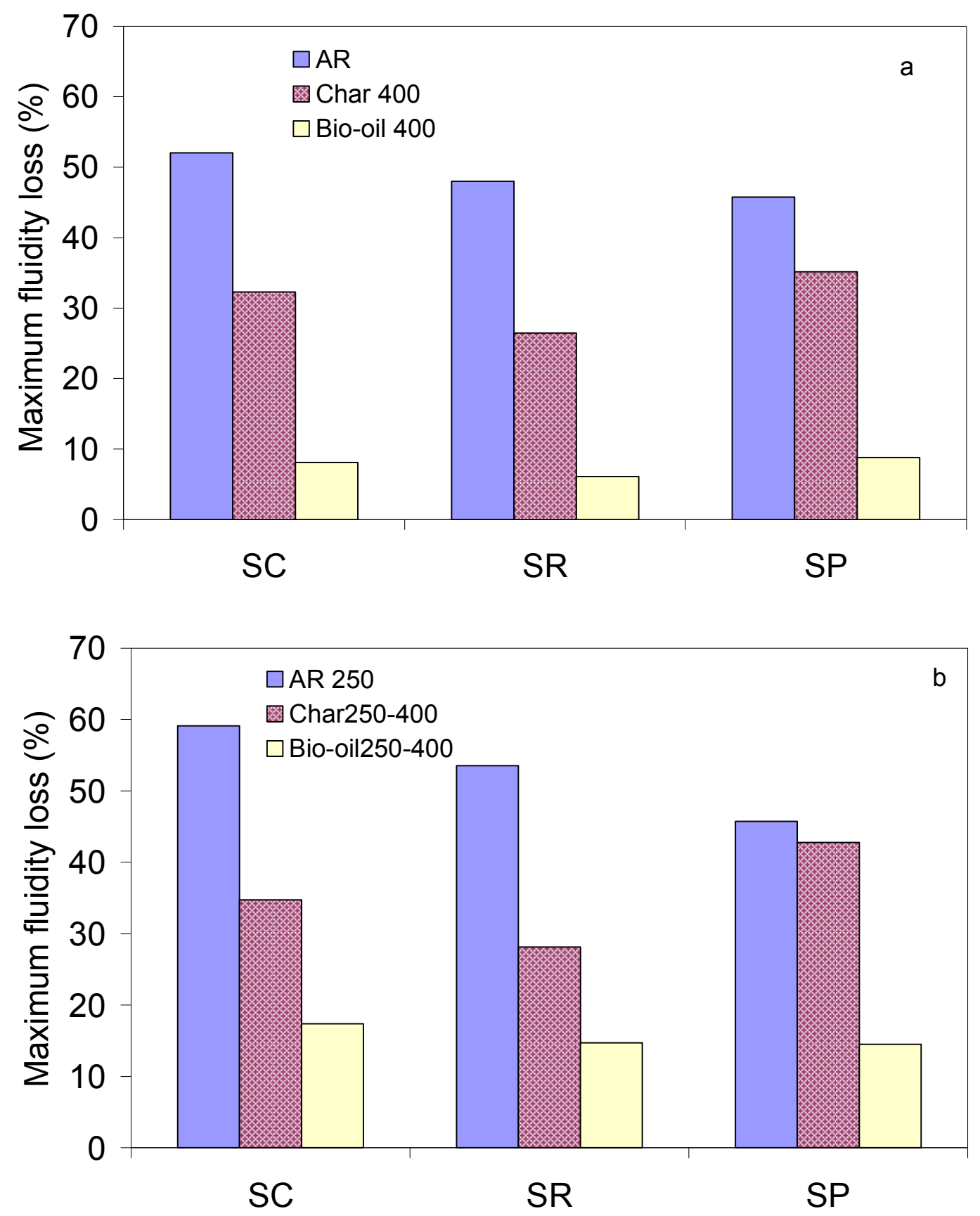

Figure 4. Variation of Gieseler maximum fluidity with the addition of chars and bio-oils obtained at $400^{\circ} \mathrm{C}$ from the as-received (AR) and heat-treated (HT) sawdusts. 


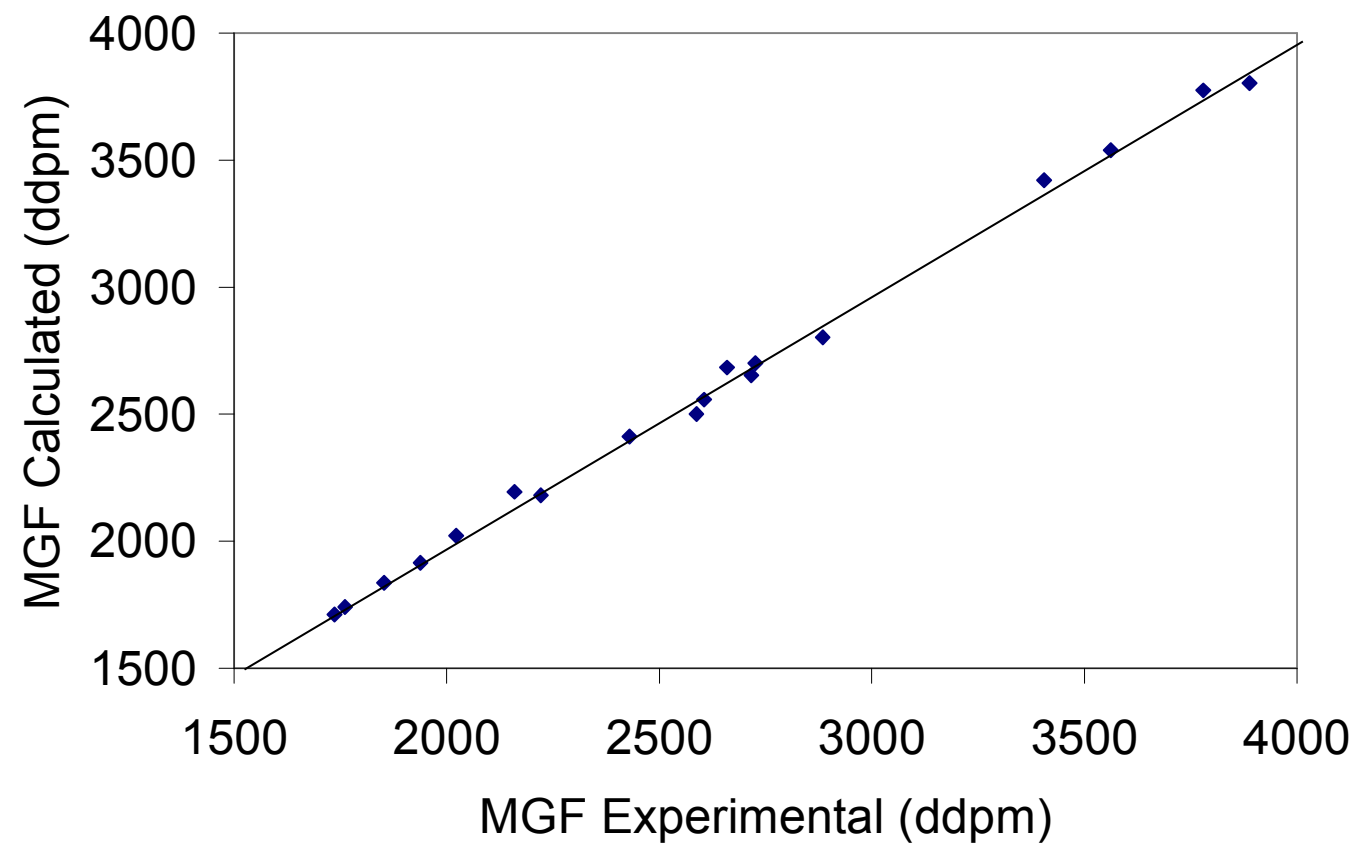

Figure 5. Relationship between the experimental maximum Gieseler fluidity (MGF) and that derived from the Gaussian curves. 

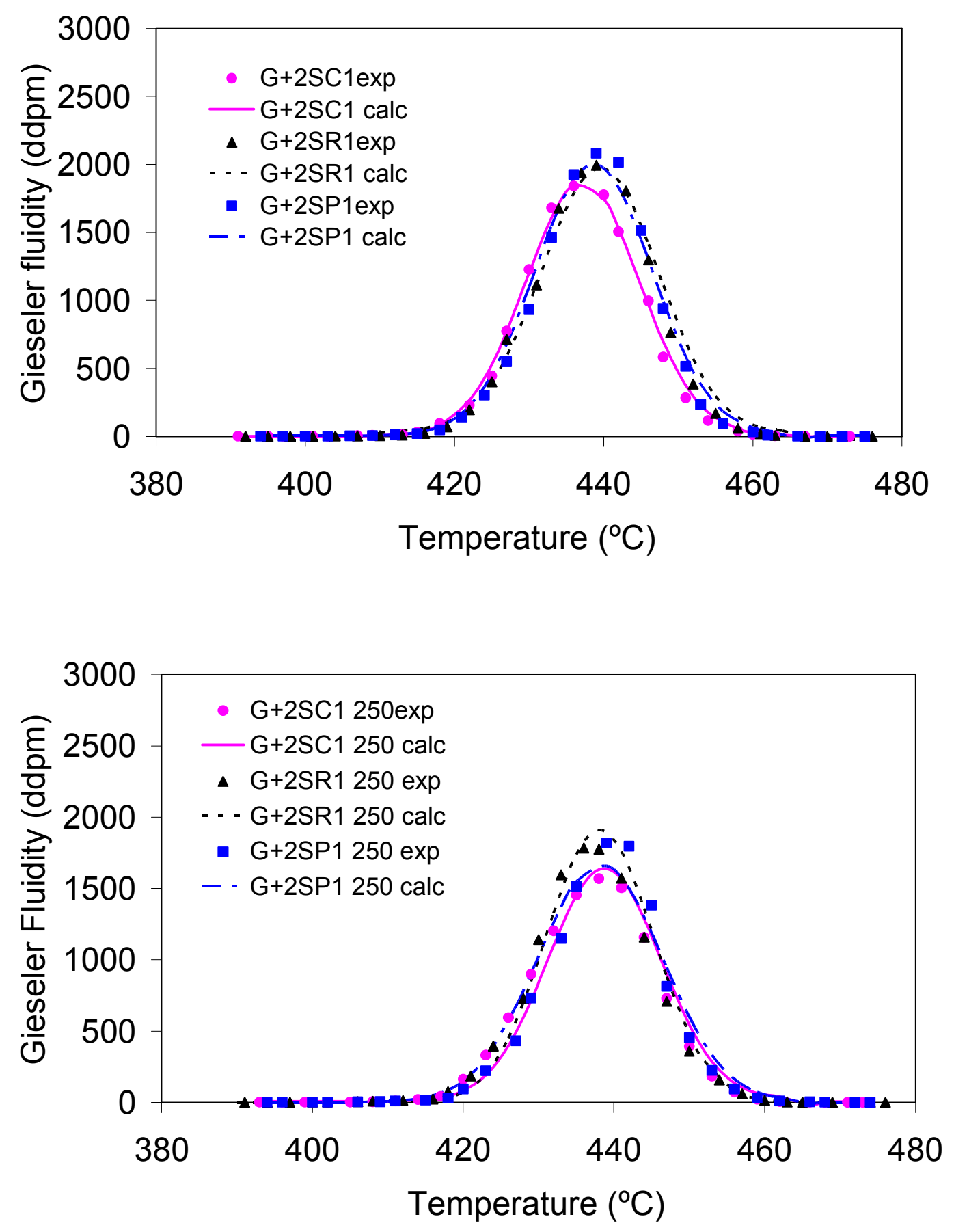

Figure 6. Comparison between the experimental maximum Gieseler fluidity and the maximum fluidity derived from the optimization of the contribution of the char and bio-oil. 